\title{
Case report: Aqueous and Vitreous amino- acid concentrations in a patient with maple syrup urine disease operated on rhegmatogenous retinal detachment
}

\author{
Menelaos G. Kanakis ${ }^{1 *}$, Helen Michelakakis ${ }^{2}$, Petros Petrou' ${ }^{1}$ Chrysanthi Koutsandrea ${ }^{1}$ and Ilias Georgalas $^{1}$
}

\begin{abstract}
Background: Maple syrup urine disease (MSUD) is a rare metabolic disorder, affecting the metabolism of branched chain amino-acids (Valine, Leukine, Isoleukine). We present a rare case of rhegmatogenous retinal detachment (RRD) in a MSUD patient.

Case presentation: We performed amino acid analysis of aqueous humour, vitreous and serum samples obtained during surgery from a 24 year old female MSUD patient successfully operated on RRD.

Serum values for a-amino-butyric acid, valine, isoleucine, leucine, tyrosine, phenylalanine, ornithine and histidine were low, while values for citrulline, methionine and lysine were borderline low, all attributed to the patient's special diet. Serum glutamate was above normal, probably due to the breakdown of glutamine to glutamate. In the aqueous and vitreous the amino acids implicated in MSUD (Valine, Leukine Isoleukine), were within normal range. Glutamate was absent in the vitreous and presented low levels in the aqueous. Glutamate has been reported to play an important role in retinal damage. Elevated glutamate levels have been reported in vitreous specimens from patients subjected to vitrectomy or buckling surgery for RRD. In MSUD, glutamate has been implicated in the pathogenesis of brain damage. Low levels of glutamate have been observed in the cerebellum of experimental MSUD animals, as well as postmortem brain tissue from a child that died of leucine intoxication. The reduction was attributed to the elevation of a-ketoisocaproic which reverses the net direction of nitrogen flow. It could be argued that this could impact on amino acid concentration in aqueous and vitreous fluids.
\end{abstract}

Conclusions: Although no definite conclusions can be drawn by this extremely rare case, the low vitreous and aqueous levels of Glutamate is an interesting finding. Further studies are needed to provide a better insight in the role of amino acids as neurotransmitters in the human eye in health and disease.

Keywords: Case report, Maple syrup urine disease, Retinal detachment, Amino acid concentration, Vitreous

\section{Background}

MSUD is a rare $(1: 200,000)$ genetic metabolic disease, caused by a defect in branched chain ketoacid dehydrogenase (BCKA), leading to elevated concentrations of the branched-chain amino acids leucine, isoleucine, and valine [1]. This enzyme is a supra enzyme complex consisting of multiple copies of four distinct subunits and is

\footnotetext{
*Correspondence: mkanakis@otenet.gr

11st Department of Ophthalmology, "G. Gennimatas" Hospital of Athens, National and Kapodistrian University of Athens, Mesogeion 154, Athens 11527, Greece

Full list of author information is available at the end of the article
}

located in the inner wall of the mitochondrion. The disease has autosomal-recessive inheritance. Ocular complications of untreated disease or late diagnosis include optic atrophy, nystagmus, ophthalmoplegia, strabismus, and cortical blindness [2].

\section{Case presentation}

A 24 year old Caucasian female was admitted to our hospital when diagnosed with Rhegmatogenous Retinal Detachment (RRD), on her left eye. The patient also suffers from maple syrup urine disease (MSUD), for which 
she has been maintained on a special diet and thiamine supplements, autismus (under treatment with quetiapine, oxcarbazepine and fluvoxamine), and ulcerative colitis (under treatment with mesalamine) (Table 1) (Additional file 1).

Dilated fundus examination revealed an inferior retinal detachment $\left(3-8^{\text {th }}\right.$ h), macula off. The detachment had been discovered 12 days ago and there were not any signs of Proliferative vitreoretinopathy (PVR). The patient was operated on successfully under general anesthesia, with 23G Vitrectomy (Constellation Vitrectomy System, Alcon Laboratories, Texas, USA), and is under follow up for the last four months. Apart from the successfully treated retinal detachment, slit lamp biomicroscopy and fundus examination were unremarkable on admission and during the follow up period.

Informed consent of the custodian (mother) was obtained, since the patient is mentally retarded due to MSUD. Undiluted vitrectomy samples (approximately $0.5 \mathrm{ml}$ ) were obtained by a conventional three-port closed vitrectomy technique, by manual suction at the beginning of the vitrectomy, before opening the infusion line of Balanced Salt Solution (BSS, Alcon Laboratories, Texas, USA), as described earlier by Diederen et al. [3]. Aqueous humour was obtained by anterior chamber paracentesis with $30 \mathrm{G}$ insulin syringe (approximately $100 \mu \mathrm{l})$. The serum sample was also obtained at the same time. The aqueous and vitreous samples were transferred to Eppendorf tubes and stored frozen, until the time of amino acid analysis, performed at the Institute of Child Health, Department of Enzymology.

Analysis was performed by ion exchange chromatography using the Biochrom 30 Amino Acid Analyser.

The results of the amino-acid analysis are presented in the Table 2: Amino acid concentration in aqueous, vitreous and serum, along with the findings of eight other studies [3-10] on amino-acid concentration in ocular fluids. This was regarded necessary, as normative data are scarce (Table 2).

We preferred to compare to normal control values as well as values obtained from patients with RRD from vitreous fluid during vitrectomy when possible, although

Table 1 Timeline (following the CARE Guidelines)

\begin{tabular}{lc}
\hline - Diagnosed with the aid of newborn screening and & 1991 \\
commenced on early dietary restriction & \\
- Repeated episodes of metabolic decompensation, & $1991-2007$ \\
usually in the context of catabolic stress associated & \\
with non-specific illness, with subsequent brain injury & \\
- Diagnosed with ulcerative colitis & 2012 \\
- Diagnosed with Rhegmatogenous Retinal Detachment & 2015 \\
- Operated on successfully under general anesthesia, & \\
with 23G Vitrectomy & \\
- Follow up (4 months) & 2016 \\
\hline
\end{tabular}

data from subretinal fluid (SRF) obtained during buckling surgery, were available. As for the aqueous humour, only values from normal controls were available. Normative data for serum levels were provided by the laboratory that performed the analysis. All values are presented as $\mu \mathrm{mol} / \mathrm{l}(\mu \mathrm{M})$. In the table we adopted the standard abbreviations for amino acids. Data regarding the patients and control groups in the aforementioned papers are presented in brief.

The patient presented with low serum levels of several amino-acids. Values for a-amino-butyric acid $(10 \mu \mathrm{M})$, valine $(146 \mu \mathrm{M})$, isoleucine $(52 \mu \mathrm{M})$, leucine $(132 \mu \mathrm{M})$, tyrosine $(58 \mu \mathrm{M})$, phenylalanine $(55 \mu \mathrm{M})$, ornithine $(22 \mu \mathrm{M})$ and histidine $(60 \mu \mathrm{M})$ were low and values for citrulline $(6 \mu \mathrm{M})$, methionine $(23 \mu \mathrm{M})$ and lysine $(168 \mu \mathrm{M})$, borderline low. Only values of Glutamic acid $(6 \mu \mathrm{M})$ were detected to be above normal values in the serum. Aminoacid concentration in the aqueous was higher than that of the vitreous, apart from glutamine $(658 \mu \mathrm{M}$ and $627 \mu \mathrm{M}$ respectively), aspartic acid ( $3 \mu \mathrm{M}$ and $3 \mu \mathrm{M}$ respectively), and citrulline $(6 \mu \mathrm{M}$ and $6 \mu \mathrm{M}$ respectively). All three amino acids implicated in the metabolic disorder (Valine, Leucine, Isoleucine), were within the reported normal ranges in the aqueous $(146 \mu \mathrm{M}, 132 \mu \mathrm{M}, 52 \mu \mathrm{M}$ respectively) and vitreous $(67 \mu \mathrm{M}, 72 \mu \mathrm{M}, 32 \mu \mathrm{M}$ respectively). Glutamate levels in were unmeasurable in the vitreous and low in the aqueous $(6 \mu \mathrm{M})$, while Taurine levels were found to be close to normal limits for aqueous $(46 \mu \mathrm{M})$ and vitreous $(21 \mu \mathrm{M})$.

The low serum levels of several amino-acids in the serum were probably due to the fact that the patient has been maintained on a strict special diet. However, values of Glutamic acid were detected to be above normal in the serum. This can be explained, since glutamine is converted to glutamate on storage, and the sum of glutamine + glutamate is well within the normal range. It could be argued that the increased level of glutamate observed most probably reflects the breakdown of glutamine during storage.

Notably there is not an established ratio of serum to aqueous or vitreous amino-acid concentration [11, 12]. On the contrary there has been reported that amino-acid concentration in the aqueous is higher than that of the vitreous, apart from glutamine [5], which seem to be confirmed by the nearly identical concentrations in our specimens (658 $\mu \mathrm{M}$ and $627 \mu \mathrm{M}$ respectively). The serum concentration of glutamine also lies within the same range $(599 \mu \mathrm{M})$ [5]. In our specimens nearly identical aminoacid concentrations between aqueous and vitreous have also been found for aspartic acid and citrulline [5].

All three amino acids implicated in the metabolic disorder (Valine, Leucine, Isoleucine), were within the reported normal ranges in the aqueous and vitreous. This is not that strange, as it has been reported that CSF 
Table 2 Amino acid concentration in aqueous, vitreous and serum

\begin{tabular}{|c|c|c|c|c|c|c|c|c|c|c|c|c|c|c|c|}
\hline \multirow{3}{*}{$\begin{array}{l}\text { Amino } \\
\text { acid }\end{array}$} & \multicolumn{4}{|c|}{ Aqueous $(\mu \mathrm{M})$} & \multicolumn{9}{|c|}{ Vitreous $(\mu \mathrm{M})$} & \multicolumn{2}{|c|}{ Serum $(\mu M)$} \\
\hline & \multirow[t]{2}{*}{$\overline{\text { MSUD }}$} & \multirow{2}{*}{$\begin{array}{l}\text { Wuu et al. } \\
\text { Aqueous } \\
\text { control }\end{array}$} & \multirow{2}{*}{$\begin{array}{l}\text { Durham }^{\text {b }} \\
\text { Aqueous } \\
\text { control }\end{array}$} & \multirow{2}{*}{$\begin{array}{l}\text { Wakabayashi } \\
\text { et al.c } \\
\text { Aqueous } \\
\text { control }\end{array}$} & \multirow[t]{2}{*}{$\overline{M S U D}$} & \multicolumn{2}{|c|}{ Bertram et al. ${ }^{d}$} & \multicolumn{2}{|c|}{ Diederen et al. e $^{\mathrm{e}}$} & \multirow{2}{*}{$\begin{array}{l}\text { Durhamb }^{\text {b }} \\
\text { Vitreous } \\
\text { control }\end{array}$} & \multirow{2}{*}{$\begin{array}{l}\text { Honkanen } \\
\text { et al. } \\
\text { Vitreous } \\
\text { control }\end{array}$} & \multirow{2}{*}{$\begin{array}{l}\text { Asensio et al. }{ }^{g} \\
\text { Vitreous } \\
\text { RD,MH,ERM }\end{array}$} & \multirow{2}{*}{$\begin{array}{l}\text { Yalcinbayir } \\
\text { et al. } \\
\text { Vitreous } \\
\text { Control }\end{array}$} & \multirow[t]{2}{*}{$\overline{M S U D}$} & \multirow{2}{*}{$\begin{array}{l}\mathrm{LAB} \\
\text { Normal }\end{array}$} \\
\hline & & & & & & $\begin{array}{l}\text { Vitreous } \\
\text { RRD }\end{array}$ & $\begin{array}{l}\text { Vitreous } \\
\text { control }\end{array}$ & $\begin{array}{l}\text { Vitreous } \\
\text { RRD }\end{array}$ & $\begin{array}{l}\text { Vitreous } \\
\text { control }\end{array}$ & & & & & & \\
\hline Pro & 45 & $16.9 \pm 15.4$ & $16 \pm 5.3$ & & U & & & & & $4 \pm 5.6$ & & & & 101 & $97-297$ \\
\hline Tau & 46 & $29.3 \pm 12$ & $39.1 \pm 11.3$ & $22.25 \pm 8.36$ & 21 & & & $26.0 \pm 7.8$ & $22.6 \pm 6.6$ & $28.8 \pm 5$ & & $11.9 \pm 1.3$ & $79(26-146)$ & 61 & $27-95$ \\
\hline Asp & 3 & $13.4 \pm 9.1$ & $1 \pm 1.5$ & $1.81 \pm 1.04$ & 3 & U & $1.1 \pm 0.8$ & $6.7 \pm 2.8$ & $6.6 \pm 2.5$ & $1.7 \pm 1.5$ & $1.4 \pm 1.0$ & $3.7 \pm 4.1$ & $47(6-70)$ & 5 & $2-9$ \\
\hline Thr & 158 & $106.7 \pm 18.9$ & $152 \pm 41.4$ & & 31 & & & & & $73.6 \pm 10.3$ & $85.5 \pm 28.4$ & $61.8 \pm 3.6$ & $385(77-519)$ & 130 & $92-180$ \\
\hline Ser & 131 & $111.2 \pm 45.3$ & $179 \pm 38.1$ & & 89 & & & & & $106 \pm 24.4$ & $103.9 \pm 24.4$ & $79.2 \pm 19.5$ & $501(96-733)$ & 99 & 89-165 \\
\hline Asn & 78 & $27.3 \pm 11.1$ & $49.2 \pm 11.5$ & & 39 & & & & & $24.3 \pm 4.3$ & $35.8 \pm 11.6$ & $19.5 \pm 8.1$ & & 80 & $32-92$ \\
\hline Glu & 6 & $39.5 \pm 18.8$ & $12 \pm 3.4$ & $2.98 \pm 1.12$ & U & $\begin{array}{l}13.4 \pm \\
11.9\end{array}$ & $1.7 \pm 0.8$ & $16.6 \pm 5.6$ & $13.1 \pm 5.2$ & $14.5 \pm 11$ & $5.2 \pm 2.3$ & $3.8 \pm 5.1$ & $20(10-82)$ & 96 & $6-62$ \\
\hline Gln & 658 & $95.9 \pm 68.9$ & $717 \pm 134$ & & 627 & & & & & & $1192.9 \pm 404.4$ & & $3386(714-4698)$ & 599 & $466-798$ \\
\hline Gly & 71 & $7 \pm 3.2$ & $16.7 \pm 3.5$ & & 5 & U & $4 \pm 2.7$ & $42.5 \pm 32.0$ & $49.4 \pm 36.3$ & $8.7 \pm 2.6$ & $8.5 \pm 2.5$ & $10.2 \pm 6.2$ & $56(15-196)$ & 256 & $147-299$ \\
\hline Ala & 227 & $182.7 \pm 91.4$ & $294 \pm 66.1$ & $105.98 \pm 9.88$ & 85 & U & $88.4 \pm 35$ & & & $126 \pm 15.6$ & $159.5 \pm 54.9$ & $31.8 \pm 10.6$ & $896(125-1842)$ & 241 & $146-494$ \\
\hline Cit & 6 & $3.8 \pm 6.6$ & $9.8 \pm 4.8$ & & 6 & & & & & $8.3 \pm 1.6$ & & & $9(5-27)$ & 18 & $19-47$ \\
\hline Abu & 10 & $10.6 \pm 5.7$ & $31.4 \pm 7.8$ & & U & & & & & $14.4 \pm 1.7$ & & & & 9 & $15-35$ \\
\hline Val & 146 & $\begin{array}{l}281.2 \pm \\
180.6\end{array}$ & $388 \pm 84.5$ & & 67 & U & $112 \pm 4.4$ & & & $174 \pm 41.3$ & & $87.5 \pm 6.5$ & $909(140-1277)$ & 95 & 179-335 \\
\hline Cys & 9 & $7.9 \pm 1.7$ & $11.2 \pm 3.5$ & & 4 & & & & & $6.5 \pm 6$ & & & & 42 & $24-54$ \\
\hline Met & 23 & $18.8 \pm 8.6$ & $44.4 \pm 9.9$ & & 13 & & & & & $24.7 \pm 5$ & $22.3 \pm 8.1$ & $13.2 \pm 3.2$ & $84(12-133)$ & 13 & $13-37$ \\
\hline Ile & 52 & $72.2 \pm 26.2$ & $79.8 \pm 6.9$ & & 32 & U & $28.3 \pm 12.0$ & & & $37.6 \pm 3.4$ & $37.9 \pm 11.6$ & $32.8 \pm 5.1$ & $220(39-317)$ & 27 & $46-90$ \\
\hline Leu & 132 & $169.5 \pm 72.2$ & $192 \pm 39.6$ & & 72 & U & $63.5 \pm 21.9$ & & & $96.1 \pm 20.5$ & $89.7 \pm 28.4$ & $76.5 \pm 5.3$ & $584(93-737)$ & 88 & $113-205$ \\
\hline Tyr & 58 & $79.2 \pm 37.6$ & $123 \pm 16.5$ & & 32 & U & $31.9 \pm 3.7$ & & & $51.8 \pm 12.3$ & $58.2 \pm 18.8$ & $41.1 \pm 6.3$ & $365(58-399)$ & 29 & $37-77$ \\
\hline Phe & 55 & $97.7 \pm 30.3$ & $119 \pm 14$ & & 28 & U & $31.7 \pm 11$ & & & $56.8 \pm 13.6$ & $44.4 \pm 14.2$ & $43.3 \pm 1.9$ & $356(66-469)$ & 29 & $46-74$ \\
\hline Orn & 22 & $15 \pm 3.4$ & $25.3 \pm 4.6$ & & 15 & & & & & $16 \pm 1.1$ & & $13.6 \pm 0.9$ & & 42 & $55-135$ \\
\hline Lys & 168 & $110.3 \pm 36.5$ & $155 \pm 23.5$ & & 114 & & & & & $105 \pm 14.4$ & $115.4 \pm 33.7$ & $87.6 \pm 4.6$ & & 137 & $135-243$ \\
\hline
\end{tabular}


Table 2 Amino acid concentration in aqueous, vitreous and serum (Continued)

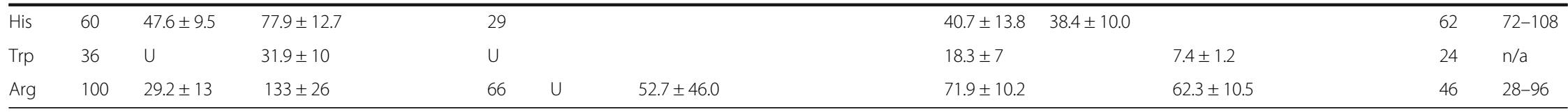

\section{MSUD maple syrup urine disease-i.e., our patient, $\mu M \mu \mathrm{mol} / \mathrm{I}, U$ unmeasurable; empty cells refer to not available data}

$M H$ macular hole, ERM epiretinal membrane, a.c. anterior chamber, RRD rhegmatogenous retinal detachment, TRD tractional retinal detachment, $P P V$ pars plana vitrectomy, $L A B($ normal) normal reference values provided by the laboratory that performed the amino acid analysis

Data regarding previous studies

a Wuu et al. [4]: Controls: Aqueous: $n=3$ (ophthalmological emergency operations - Chinese population)

${ }^{b}$ Durham [5]: Controls: Aqueous: normal eyes, a.c. paracentesis $(n=9$, mean age 28y (2.5-77). Vitreous: procedure with vitreous loss $(n=3$, Marfan/cataract/enucleation, age $=40 / 21 / 35$ y)

c Wakabayashi et al. [6]: Controls: cataract without other ocular disease $(n=9$, age $66.1 \pm 12.8 \mathrm{y}$. $)$

d Bertram et al. [7]: PPV for RRD ( $n=5$, age $=63.8 \pm 15.5 \mathrm{y}$, duration $52.4 \pm 65.4$ days). Controls: vitrectomy for MH $(n=7)$ or ERM $(n=3)($ age $=66.1 \pm 12.1$ y.

e Diederen et al. [3]: PPV for primary retinal detachment $(n=114$, age $=58.2 \pm 15.1$ y., duration $43.6 \pm 72.1$ days). Controls: PPV for MH or ERM $(n=52$, age $=51.3 \pm 14.0 \mathrm{y}$.

f Honkanen et al. [8]: Controls: PPV for MH ( $n=10$ [2 RRD]), ERM( $n=6[2$ TRD]), MH and ERM $(n=1)$. Total number of eyes: $(n=17$, age $=68 \pm 14$ y.)

${ }^{9}$ Asensio et al. [9]: 64 eyes with RRD $n=(45), \mathrm{MH}(n=5)$ and $\operatorname{ERM}(n=14)$. Age $=67.7 \pm 14.2 \mathrm{y}$. [No statistically significant difference neither between groups, nor regarding age]

${ }^{h}$ Yalcinbayir et al. [10]: Controls: PPV for MH( $\left.n=6\right)$, subluxated lens $(n=1)$. Age $=67.3 \pm 3.8$ y 
amino acid concentrations do not reflect serum concentration, and blood-brain barrier has its equivalent in the eye in the form of blood-aqueous and blood-retina barriers [13].

On the other hand, presumably important factors that determine the concentration of amino acids in aqueous and vitreous are not yet clear. The active efflux of amino acids in the aqueous $[14,15]$, combined with the turnover rate of the aqueous and the sink effect of the vitreous itself [15], as well as the variability of amino acid concentration in the normal vitreous comprise a dynamic equilibrium system.

Another interesting aspect of our results is the absence of glutamate in the vitreous, and the low levels in the aqueous. Glutamate has been reported to play an important role in retinal damage, and elevated glutamate levels have been reported in vitreous specimens from patients subjected to vitrectomy for RRD. [3, 7] In RRD patients treated with scleral buckle, elevated levels of glutamate in Subretinal fluid (SRF) have also been reported. In these patients SRF glutamate levels seem to rise in parallel with the duration of the detachment [10]. Elevated glutamate levels in the aqueous have also been reported in cases of retinal artery occlusion [6], and in glaucoma patients [8].

Glutamate is the main excitatory neurotransmitter in the central nervous system (CNS) and the retina [16], and is constantly released from the synapses of photoreceptors but also bipolar and amacrine cells, in a $\mathrm{Ca}^{+2}$ dependent manner. It also seems that there is a $\mathrm{Ca}^{+2}$-independent mechanism under stress conditions (hypoxia), by reversal of the plasma membrane uptake carrier. Glutamate is normally removed from the extracellular space by the glutamate/aspartate transporter system, by neuronal and glial cells. Failure to remove glutamate from the extracellular space, causes an increase in glutamate concentration and leads to overstimulation of $\mathrm{N}$-methylD-aspartate receptor, leading to $\mathrm{Ca}^{+2}$ influx into cells. The increased intracellular $\mathrm{Ca}^{+2}$ leads to the production of nitric oxide (NO), that interacts with oxygen to form extremely toxic free radicals resulting in retinal neuronal death $[17,18]$. Regarding retinal detachment, an acute efflux of neuronal glutamate, caused by injury-mediated acute depolarization and release of glutamate vesicles may also trigger the above mechanism and lead to excitotoxic cell death in the detached retina $[18,19]$.

In MSUD glutamate has been implicated in the pathogenesis of brain damage.

Low levels of glutamate have been observed in the cerebellum of experimental MSUD animals [20, 21] as well as postmortem brain tissue from a child that died of leucine intoxication [22]. The reduction was suggested to result from the elevation of a ketoisocaproic which reverses the net direction of nitrogen flow. It could be argued that this could impact on amino acid concentration in aqueous and vitreous fluids. Although a correlation was found between increased vitreous glutamate and a lower pre-operative visual acuity, this was not the case regarding visual outcome.

Diederen et al. [3] detected that apart from glutamate, taurine levels were also increased in RRD. In our patient taurine levels were found to be within normal limits. Taurine is one of the most abundant amino acids in the brain and retina, although it is one of the few amino acids not incorporated into proteins. In the retina, taurine is critical for photoreceptor development and acts as a cytoprotectant against stress-related neuronal damage [23].

\section{Conclusions}

It is obvious that no definite conclusions regarding amino acid concentration in aqueous and vitreous of MSUD patients with RRD can be drawn by this case. We present our data not only because this is a rare case of RRD in a MSUD patient (no other case has been reported till now according to our best knowledge), but also to draw attention to rare diseases and metabolic disorders with ophthalmological complications that, if studied adequately, may provide useful data for the patients care, as well as a better insight in the role of amino acids as neurotransmitters in the human eye.

\section{Additional file}

Additional file 1: Care flow diagram. (DOCX $54 \mathrm{~kb}$ )

\section{Abbreviations}

a.c.: Anterior chamber; Abu: a-Aminobutyric acid; Ala: Alanine; Arg: Arginine; Asn: Asparagine; Asp: Aspartic acid (Aspartate); BCKA: Branched chain ketoacid dehydrogenase; BSS: Balanced salt solution; Cit: Citrulline; Cys: Cysteine; ERM: Epiretinal membrane; Gln: Glutamine; Glu: Glutamate; Gly: Glycine; His: Histidine; lle: Isoleucine; LAB: The laboratory that performed the amino acid analysis; Leu: Leucine; Lys: Lysine; Met: Methionine; MH: Macular hole; MSUD: Maple syrup urine disease; NO: Nitric oxide; Orn: Ornithine; Phe: Phenylalanine; PPV: Pars plana vitrectomy; Pro: Proline; RRD: Rhegmatogenous retinal detachment; Ser: Serine; SRF: Subretinal fluid; Tau: Taurine; Thr: Threonine; TRD: Tractional retinal detachment; Trp: Tryptophan; Tyr: Tyrosine; Val: Valine; $\mu \mathrm{M}$ : $\mu \mathrm{mol} / \mathrm{I}$

\section{Acknowledgements}

The authors would like to thank the scientific stuff of the Dept Enzymology and Cellular Function, Institute of Child Health for processing the samples.

\section{Authors' contributions}

IG operated on the patient, initiated and supervised the study. CK critically revised the manuscript and contributed to the manuscript with her expertise. HM performed the sample analysis, revised the manuscript and contributed to the manuscript with her expertise. PP collected and analyzed data and revised the manuscript. MK coordinated the data collection, analyzed the data and wrote this manuscript. All authors have read and approved the final manuscript.

Competing interests

The authors declare that they have no competing interests. 


\section{Consent for publication}

Written informed consent of the guardian (mother) was obtained. (The patient is mentally retarded due to MSUD)

\section{Ethics approval and consent to participate}

This study was approved by the Ethics Committee Gennimatas General Hospital, and adheres to the tenets of the Declaration of Helsinki.

\section{Author details}

11st Department of Ophthalmology, "G. Gennimatas" Hospital of Athens, National and Kapodistrian University of Athens, Mesogeion 154, Athens 11527, Greece. ${ }^{2}$ Department Enzymology and Cellular Function, Institute of Child Health, 7 Fokidos street, Athens 11526, Greece.

Received: 18 February 2016 Accepted: 10 June 2016

\section{Published online: 03 October 2016}

\section{References}

1. Korein J, Sansaricq C, Kalmijn M, Honig J, Lange B. Maple syrup urine disease: clinical, eeg, and plasma amino acid correlations with a theoretical mechanism of acute neurotoxicity. Int J Neurosci. 1994;79:21-45.

2. Burke JP, O'Keefe M, Bowell R, Naughten ER. Ophthalmic findings in maple syrup urine disease. Metab Pediatr Syst Ophthalmol. 1991;14:12-5.

3. Diederen $\mathrm{RMH}$, La Heij EC, Deutz NEP, Kijlstra A, Kessels AGH, van Eijk HMH, et al. Increased glutamate levels in the vitreous of patients with retinal detachment. Exp Eye Res. 2006:83:45-50.

4. Wuu JA, Wen LY, Chuang TY, Chang GG. Amino acid concentrations in serum and aqueous humor from subjects with extreme myopia or senile cataract. Clin Chem. 1988;34:1610-3.

5. Durham DG. Distribution of free amino acids in human intraocular fluids. Trans Am Ophthalmol Soc. 1970;68:462-500.

6. Wakabayashi Y, Yagihashi T, Kezuka J, Muramatsu D, Usui M, Iwasaki T. Glutamate levels in aqueous humor of patients with retinal artery occlusion. Retina. 2006;26:432-6.

7. Bertram KM, Bula DV, Pulido JS, Shippy SA, Gautam S, Lu MJ, et al. Aminoacid levels in subretinal and vitreous fluid of patients with retinal detachment. Eye. 2008:22:582-9.

8. Honkanen RA, Baruah S, Zimmerman MB, Khanna CL, Weaver YK, Narkiewicz $J$, et al. Vitreous amino acid concentrations in patients with glaucoma undergoing vitrectomy. Arch Ophthalmol. 2003;121:183-8.

9. Asensio Sánchez VM, Corral Azor A, Aguirre Aragón B, De Paz García M. Amino acid concentrations in the vitreous body in control subjects. Arch Soc Esp Oftalmol. 2002;77:611-6.

10. Yalcinbayir O, Buyukuysal RL, Gelisken O, Buyukuysal C, Can B. Amino acid and vascular endothelial growth factor levels in subretinal fluid in rhegmatogenous retinal detachment. Mol Vision. 2014;20:1357-65.

11. Schonheyder F, Ehlers N, Hust B. Remarks on the aqueous humor/plasma ratios for amino acids and related compounds in patients with various chronic ocular disorders. Acta Ophthalmol. 1975;53:627-34.

12. Aydemir O, Türkçüoǧlu $P$, Güler $M$, Celiker Ü, Üstündaǧ B, Yilmaz T, et al. Plasma and vitreous homocysteine concentrations in patients with proliferative diabetic retinopathy. Retina. 2008;28:741-3.

13. Vogel KR, Arning E, Wasek BL, McPherson S, Bottiglieri T, Gibson KM. Brainblood amino acid correlates following protein restriction in murine maple syrup urine disease. Orphanet J Rare Dis. 2014;9:73.

14. Hu RG, Lim JC, Kalloniatis M, Donaldson PJ. Cellular localization of glutamate and glutamine metabolism and transport pathways in the rat ciliary epithelium. Invest Ophthalmol Vis Sci. 2011;52:3345-53.

15. Reddy VN, Thompson MR, Chakrapani B. Amino acid transport across blood aqueous barrier of mammalian species. Exp Eye Res. 1977;25:555-62.

16. Neal MJ. Amino acid transmitter substances in the vertebrate retina. Gen Pharmacol. 1976;7:321-32.

17. Kashii S. The role of nitric oxide in the ischemic retina. Nippon Ganka Gakkai Zasshi. 1995:99:1361-76.

18. Nicholls D, Attwell D. The release and uptake of excitatory amino acids. Trends Pharmacol Sci. 1990;11:462-8.

19. Sherry DM, Townes-Anderson E. Rapid glutamatergic alterations in the neural retina induced by retinal detachment. Invest Ophthalmol Vis Sci. 2000;41:2779-90.

20. Dodd PR, Williams SH, Gundlach AL, Harper PA, Healy PJ, Dennis JA, et al. Glutamate and gamma-aminobutyric acid neurotransmitter systems in the acute phase of maple syrup urine disease and citrullinemia encephalopathies in newborn calves. J Neurochem. 1992:59:582-90.

21. Zinnanti WJ, Lazovic J, Griffin K, Skvorak KJ, Paul HS, Homanics GE, et al. Dual mechanism of brain injury and novel treatment strategy in maple syrup urine disease. Brain. 2009;132:903-18.

22. Prensky AL, Moser HW. Brain lipids, proteolipids, and free amino acids in maple syrup urine disease. J Neurochem. 1966;13:863-74.

23. Ripps H, Shen W. Review: Taurine: a "very essential" amino acid. Mol Vision. 2012:18:2673-86.

\section{Submit your next manuscript to BioMed Central and we will help you at every step:}

- We accept pre-submission inquiries

- Our selector tool helps you to find the most relevant journal

- We provide round the clock customer support

- Convenient online submission

- Thorough peer review

- Inclusion in PubMed and all major indexing services

- Maximum visibility for your research

Submit your manuscript at www.biomedcentral.com/submit 